(2) Open Access Full Text Article

\title{
Improvement of dermal parameters in aged skin after oral use of a nutrient supplement
}

This article was published in the following Dove Press journal:

Clinical, Cosmetic and Investigational Dermatology

\section{Flávia Alvim Sant'Anna \\ Addor ${ }^{\prime}$ \\ Juliana Cotta Vieira² \\ Camila Sirieiro Abreu Melo \\ 'MEDCIN Research, Osasco, Brazil; ${ }^{2}$ Farmoquímica S.A., Rio de Janeiro, Brazil}

Purpose: Skin aging is a progressive and degenerative process caused by a decrease in the physiological functions of the skin tissue. In addition, environmental factors as well as concomitant diseases and lifestyle (nutrition, sedentary lifestyle, smoking, etc) negatively impact the aging process. An association between oral administration of collagen peptides combined with vitamin C and extracts of Hibiscus sabdariffa and Aristotelia chilensis (Delphynol ${ }^{\mathbb{}}$ ) (Eximia Firmalize Age complex ${ }^{\circledR}$ ) on dermal thickness was studied and the improvement in aging signs was evaluated.

Patients and methods: Female adult patients received an oral nutritional supplement containing collagen peptides, vitamin C, H. sabdariffa, and A. chilensis (Delphynol) in a sachet and were instructed to consume 1 sachet diluted in $200 \mathrm{~mL}$ of water once daily for 12 weeks. They were evaluated clinically, by high frequency ultrasound and cutometry.

Results: There was a significant improvement of firmness and elasticity and an increase in dermal thickness by ultrasound after 3 months of use.

Conclusion: The association of collagen peptides, vitamin $\mathrm{C}, H$. sabdariffa and A. chilensis (Delphynol) could improve the signs of dermal skin aging.

Keywords: aging, collagen, ultrasound, dermis, antioxidant, flavonoids, peptides

\section{Introduction}

Skin aging is a progressive and degenerative process caused by a decrease in the physiological functions of skin tissue (dermis and epidermis). In addition, environmental factors, such as sun exposure and pollution, as well as concomitant diseases and lifestyle factors (nutrition, sedentary lifestyle, smoking, etc.) negatively affect skin tissue by increasing oxidation levels, thus leading to a chronic inflammatory state of the skin. This is often subclinical; however, these factors accelerate the aging process and increase the likelihood of comorbidities such as tumors. This is the concept for inflammaging, a term coined by Franceschi et al. ${ }^{1,2}$

Metalloproteinases can aggravate the physiological decrease in the synthesis of collagen and other extracellular matrix elements in the dermis, which is characteristic of chronological aging (intrinsic). The expression of metalloproteinases increases owing to photodamage and inflammatory mechanisms. ${ }^{3}$

Menopause is also a factor that accelerates degenerative changes in dermal collagen and thickness, resulting in the progressive loss of collagen. The highest loss (of up to $30 \%$ ) is observed in the first 5 years, followed by a $1 \%-2 \%$ loss of collagen annually. Hormone replacement therapy leads to partial recovery; however, not all patients can undergo this therapy. ${ }^{4}$
Correspondence: Flávia Alvim Sant'Anna Addor

MEDCIN Research, 176th Alameda Das Bauhinias, Tamboré 10, Osasco,

Sao Paulo 06544-540, Brazil

Tel +5 5I I 999796775

Email Flavia.addor@medcin.com.br 
Although oral collagen is widely used in the treatment of skin aging, there is still lack of scientific information about the effects.

Because of the development of technologies that allowed the isolation of peptides for oral intake, this topic is once again being discussed due to the introduction of a new generation of collagen supplements; peptides can increase the expression of certain molecules linked to collagen synthesis; their combination with other substances, such as vitamins and phytoextracts, could enhance this effect.

Similarly, herbal extracts that have antioxidant and antiinflammatory effects have been studied, with some standing out not only for their effectiveness but also for their safety; their use is an alternative approach in conditions associated with inflammaging. 5,6

This study was conducted to evaluate the impact of the intake of collagen peptides combined with vitamin $\mathrm{C}$ and extracts of Hibiscus sabdariffa and Aristotelia chilensis (Delphynol®, Anklam Extrakt GmbH, Anklam, Germany) (Eximia Firmalize Age complex ${ }^{\circledR}$, Farmoquímica S.A., Rio de Janeiro, Brazil) on dermal thickness and to evaluate the consequent improvement in the signs of aging.

\section{Methods}

\section{Study design overview}

The approval to conduct this study was obtained from São Francisco University Ethics Committee prior to the study, which was conducted following Good Clinical Practices. ${ }^{7}$

Females who complained about and had clinical signs of aging were invited to this open, blinded, and noncomparative study, from November 2016 to February 2017.

\section{Population}

Thirty-five females who complained about some degree of skin aging and facial sagging skin were involved. They were included after signing an informed consent form. These patients were aged between 35 and 65 years and did not undergo any dermatological treatment until 4 weeks before the study. Patients using corticosteroids and immunosuppressants and having active endocrinopathies or any medical condition that could interfere with evaluations were excluded.

\section{Intervention}

The patients received an oral nutritional supplement containing collagen peptides, vitamin $\mathrm{C}, H$. sabdariffa, and A. chilensis (Delphynol) in a sachet and were instructed to consume one sachet diluted in $200 \mathrm{~mL}$ of water once a day for 12 weeks.

\section{Outcomes}

The primary outcome, ie, improvement in skin mechanical properties and dermal thickness, was measured by cutometry and ultrasound on the submental and malar regions (right or left), respectively. Measurements were performed at the beginning of the study and then every month for up to 12 weeks until the end of the study.

The secondary outcome was improvement in skin based on a subjective evaluation.

\section{Procedures}

The patients were evaluated for the presence of adverse reactions and effectiveness of treatment by evaluating parameters such as facial skin firmness, elasticity, and texture through a questionnaire with four scores: 1=worsening, 2=slight improvement, $3=$ moderate improvement, and 4=significant improvement. On the last visit, the patients also assessed regarding the product characteristics (taste and solubility). The instrumental methods used for the evaluations are as follows:

\section{Cutometry}

This is a noninvasive method to evaluate the skin's mechanical properties; it is based on the degree of skin deformity, which is represented by skin firmness and elasticity. The evaluations were always performed in triplicate by the same investigators using Cutometer ${ }^{\circledR}$ MPA 580 (Courage \& Khazaka, Cologne, Germany), and an average measurement was obtained. ${ }^{8}$

\section{Ultrasonography}

Ultrasound exams were performed using Voluson E equipment (GE Healthcare, Little Chalfont, UK) with a multichannel color Doppler and a transducer of up to $15 \mathrm{MHz}$, which allows the use of a higher resolution with low penetration. ${ }^{9}$

The same investigator who evaluated the morphological characteristics and thickness of the dermis performed all evaluations. Evaluations were performed in triplicate, and an average measurement was obtained for subsequent comparisons between different study periods.

Assessment by ultrasonography was performed in previously standardized areas: median submental and right and left malar regions, at the midpoint of an imaginary line in the nasal wing of the prominent zygomatic bone. Cutometry measurements were performed in the right or left malar regions. 


\section{Sample size and statistical analysis}

Based on previous studies, we expected the cutometry values of skin firmness to decrease and those of elasticity to increase. The evaluation of the 35 patients was expected to detect a difference of at least $15 \%$ in both parameters between the evaluation periods at a $95 \% \mathrm{CI}$. The ultrasound values of dermal thickness were expected to increase by $5 \%$ at a $95 \% \mathrm{CI}$.

To evaluate the normality of data distribution, the Shapiro-Wilk test was used to compare the effect of time, whereas the Wilcoxon test was performed using data medians at a significance level of $95 \%$. Student's $t$-test was also used for analysis of ultrasonography and cutometry data.

\section{Results}

Of the 35 patients who were included at the beginning of this study, 31 completed all evaluations. These patients were aged between 35 and 65 years (mean age, 51 years). There were 25 Caucasian and 6 African American females. No severe adverse reactions were related by the patients or observed during the study.

Treatment was discontinued in a third patient who was lost to follow-up. Another patient complained about mild and persistent abdominal pain, which was deemed to be related to the treatment because there was complete pain resolution after treatment. There was no need for providing any concomitant medication.

During cutometry, the parameter firmness showed a mean improvement (reduction in measurements) of $10.28 \%$ compared with measurements obtained at the beginning of the study in the first evaluation; however, this improvement was not statistically significant $(p=0.189)$. At the 8 -week evaluation, the mean improvement was $27.82 \%$, which was statistically significant ( $p=0.002$ ). In the final evaluation, a significant $38.31 \%$ improvement was observed $(p<0.001)$ (Figure 1).

The parameter elasticity showed a mean improvement (increase in measurements) of $20.86 \%$ compared with measurements obtained at the beginning of the study in the first evaluation; this improvement was statistically significant $(p=0.001)$. At the 8 -week evaluation, the mean improvement was $17.8 \%$, which was also statistically significant $(p=0.022)$. In the final evaluation, a significant mean improvement of $39.41 \%$ was detected $(p<0.001)$ (Figure 2$)$.

In the ultrasound evaluations, measurements performed in the submental area showed a mean improvement of $6.07 \%$ compared with measurements obtained at the beginning of the study in the first month; this improvement was statistically significant ( $p=0.007)$. In the 8 -week evaluation, the mean improvement was $11.32 \%$, which was also statistically significant $(p<0.001)$. In the final evaluation, a significant mean improvement of $22.38 \%$ was observed $(p<0.001)$ (Figure 3 ).

In the 4-week evaluation, the mean improvement in measurements performed in the malar area was $5.81 \%$, compared with measurements obtained at the beginning of the study in the first month; this improvement was statistically significant $(p=0.001)$. In the 8 -week evaluation, the mean improvement was $14.69 \%$, which was also statistically significant $(p<0.001)$. In the final 12-week evaluation, a significant mean improvement of $24.97 \%$ was obtained $(p<0.001)$ (Figure 4$)$.

Figures 5 and 6 show the improvement in the submental and malar regions with time, respectively.

The subjective evaluation of the overall skin appearance showed that $48.4 \%$ and $90.3 \%$ of the patients noticed a

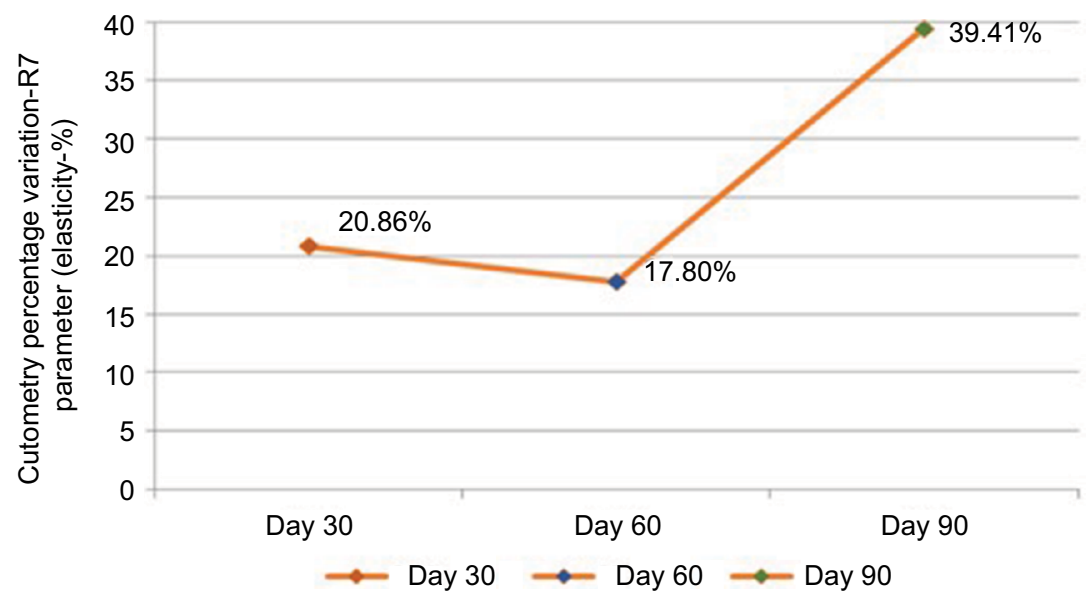

Figure I Mean percentage of improvement in skin firmness measured by cutometry $(n=3 \mid)$ Notes: Values were measured on days 30,60 , and 90 


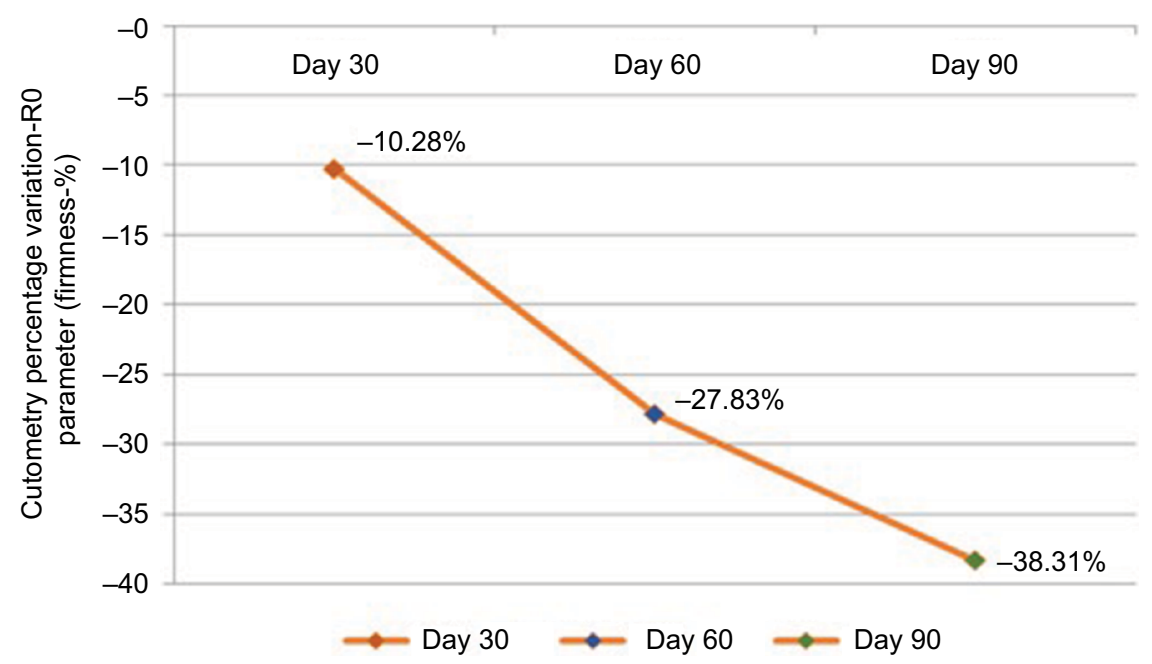

Figure 2 Mean percentage of improvement in elasticity measured by cutometry $(n=31)$.

Notes: Values were measured on days 30,60 , and 90.

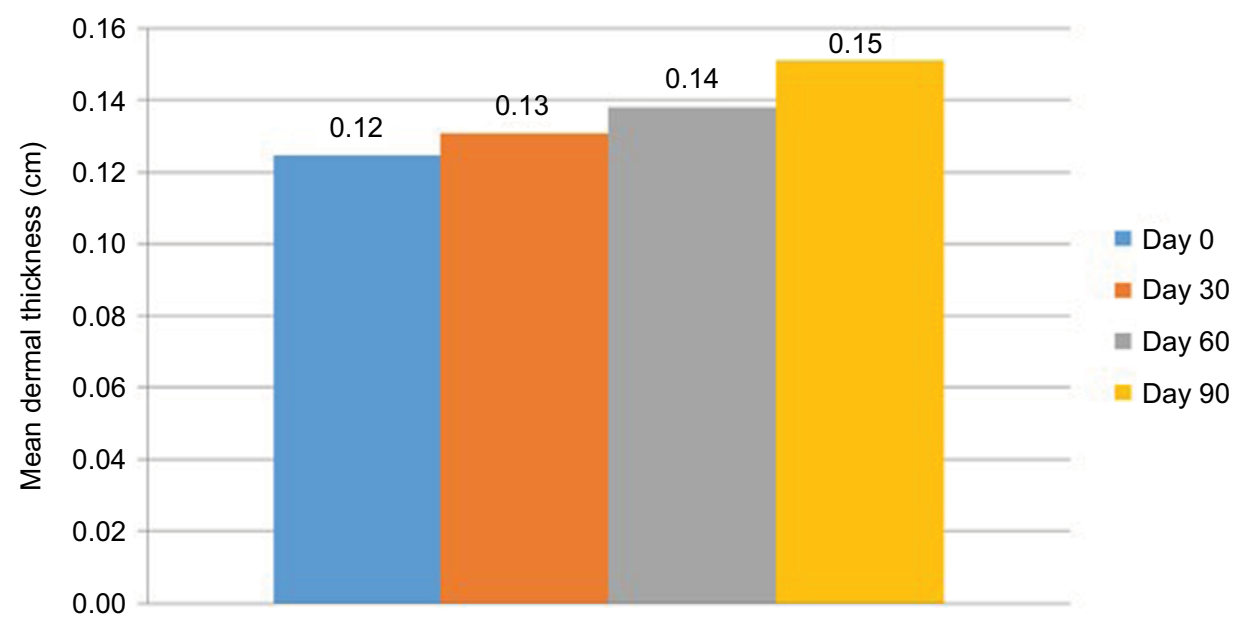

Figure 3 Mean dermal thickness in the submental region measured by ultrasound $(n=31)$.

Notes: Values were measured on days $0,30,60$, and 90.

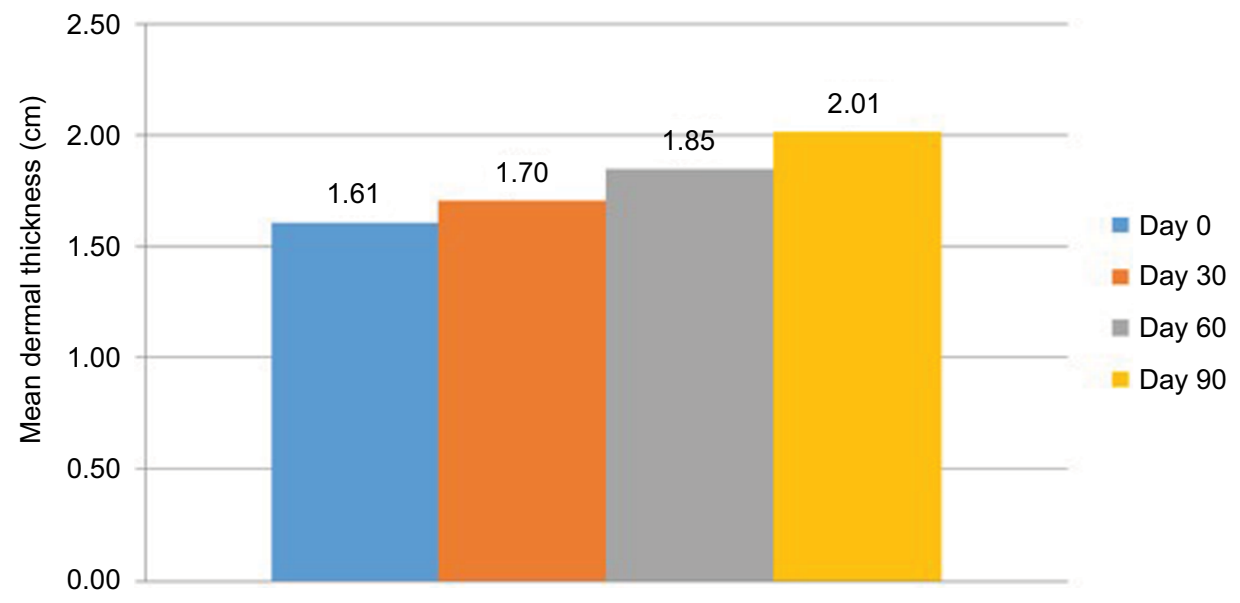

Figure 4 Mean dermal thickness in the malar region measured by ultrasound $(n=31)$.

Notes: Measurement was done by ultrasound on days $0,30,60$, and 90 of treatment. 


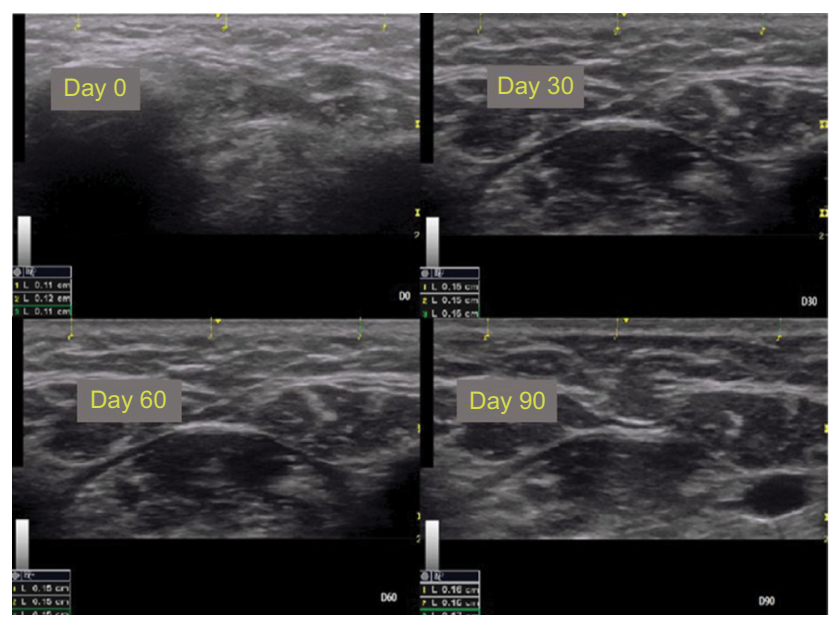

Figure 5 Ultrasound images of the submental region (patient I).

Notes: Observe the measures in triplicate in each image.

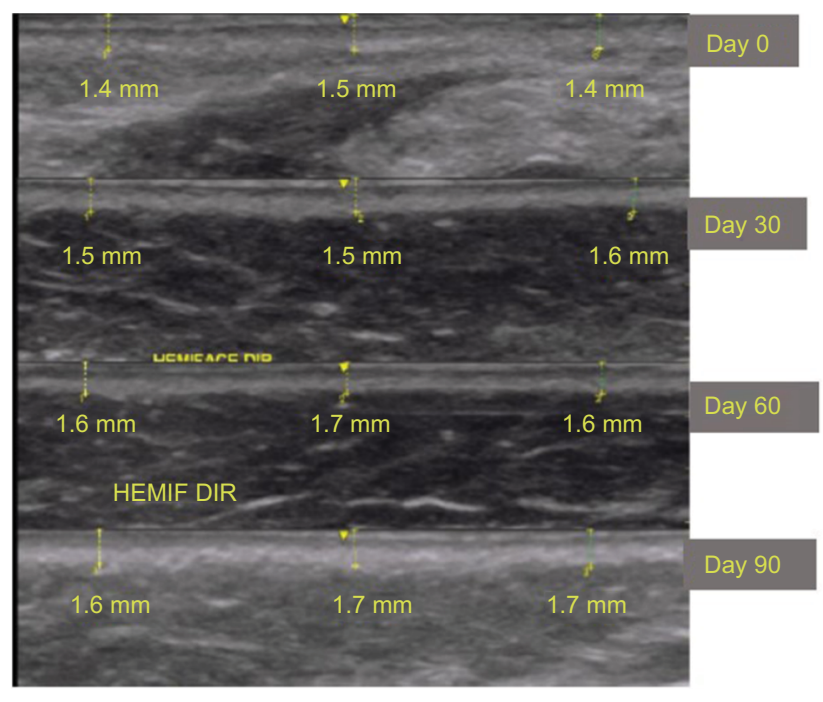

Figure 6 Ultrasound images of the malar region (in detail) in patient I. Notes: Measurements were obtained in triplicate.

moderate-to-significant improvement in the skin after 4 and 8 weeks, respectively. Identical results were also noticed after 12 weeks in the final evaluation.

With regard to skin elasticity, $58 \%$ of the patients perceived a moderate-to-significant improvement after 4 weeks; this percentage was $83.9 \%$ at 8 weeks and $93.5 \%$ at the end of the study.

With regard to facial skin firmness, $64.52 \%$ and $93.5 \%$ of the patients noticed a moderate-to-significant improvement after 4 and 8 weeks of treatment, respectively. Identical results were noticed after 12 weeks in the final evaluation.

The patients were also asked about product solubility and taste. Solubility was evaluated based on the difficulty in dissolving the sachet in $200 \mathrm{~mL}$ of water, which $87 \%$ of the patients reported as being easy or very easy. Regarding taste, $87 \%$ of the patients considered the product to taste good or very good.

\section{Discussion}

This study showed that treatment with an oral formulation containing collagen peptides, vitamin $\mathrm{C}$, and extracts of H. sabdariffa and A. chilensis (Delphynol) led to a significant improvement in the mechanical properties of the skin and in dermal thickness. Furthermore, the patients noticed an improvement in the overall appearance of aged skin, skin elasticity, and skin firmness.

The patients also experienced significant improvement in the overall appearance of the skin over time, particularly with respect to skin firmness and elasticity after 3 months of treatment. With regard to the ease of preparation and ingestion of the product, $87 \%$ of the patients reported that this factor contributed to adhering to treatment.

Nishimoto et a $1^{10}$ used a Wistar rat model to demonstrate the synthesis of collagen based on the hydroxyproline content. They showed that the administration of collagen peptides in rats had a more significant effect on skin collagen synthesis than the administration of gelatin, the level of which was similar than that of the placebo.

Collagen peptides are very similar to collagen, particularly to type I collagen found in the dermis. Therefore, they have the ability to promote collagen type I synthesis, playing a positive role in improving the signs of aging and even in other disorders that involve tissue repair in the dermis. ${ }^{11,12}$

The collagen peptide evaluated in the present study comprised 18 amino acids found in type I collagen, of which eight are essential amino acids. Glycine, proline, and hydroxyproline are the most abundant amino acids, comprising nearly $50 \%$ of the total amino acid composition of the collagen peptide. ${ }^{13}$

Specific dipeptides generated from the digestion of collagen, such as glycine-glutamate and proline-hydroxyproline, are chemotactic for dermal fibroblasts, signaling the "destruction" of collagen and thereby the activation of fibroblasts. ${ }^{14}$

Moreover, increased synthesis of hyaluronic acid and glycosaminoglycans leads to the activation of hyaluronan synthase $2 .{ }^{15,16}$

Vitamin C is widely known to stimulate the proliferation of fibroblasts. ${ }^{17}$

In the 1980s, Pinnel et a $\mathrm{l}^{18}$ showed that L-ascorbic acid induced the synthesis of procollagen in cultured dermal fibroblasts.

The plant species $H$. sabdariffa, traditionally used in food because of its taste, exhibits antioxidant, lipolytic, 
hypoglycemic, and diuretic properties in in vitro models. It can also reduce insulin resistance because of its high content in polyphenols such as phenolic acids and proanthocyanidins. ${ }^{19}$

However, its broad antioxidant action is due to its combination with other compounds present in the extract. The powerful antioxidant action mechanism of $H$. sabdariffa has been studied in tumors, and its major antioxidant compounds have been isolated: chlorogenic, neochlorogenic, and cryptochlorogenic acid; rutin; and isoquercitin. ${ }^{20}$

Delphinidin is an anthocyanidin found in some plants such as pomegranate and grape; however, its main source is maqui berry (Aristotelia sinensis). This plant is endemic to Chile and is part of the diet of Mapuche Indians and some of their rituals. This is one of the populations with the longest life spans in the world. ${ }^{21}$

Delphinol is a standardized maqui berry extract that provides a higher concentration of flavonoid delphinidin, ie, at least $25 \%$ of delphinidins and $35 \%$ of total anthocyanidins..$^{22,23}$

In addition to its powerful antioxidant action, delphinidin acts on important stages of inflammation during aging. Its main mechanisms of action are as follows:

1. It increases the expression of endothelial nitric acid synthase and reduces the expression of endothelin 1, thus improving tissue perfusion. ${ }^{24}$

2. It inhibits the expression of the cell adhesion molecules ICAM and VCAM, COX-2 when the skin is exposed to ultraviolet radiation, and dermal metalloproteinases..$^{25,26}$

When hibiscus, vitamin $\mathrm{C}$, and collagen peptides are combined as an oral supplement, they showed a positive effect on the human dermis, wherein patients had high tolerance and adhered to the treatment.

\section{Conclusion}

We conclude that the daily intake of one sachet of our oral nutritional supplement diluted in water for 3 months significantly improves dermal thickness, skin firmness, and elasticity, with most patients noticing an overall improvement in their skin after 4 weeks of treatment, which contributed to treatment adherence and compliance.

Supplements such as the product evaluated herein, which combine molecules with synergistic activities and promote the neutralization of harmful external stimuli, antiinflammatory effects, and protein synthesis, are a rational and safe choice for adjuvant treatment for skin aging and chronic inflammation associated with skin aging (inflammaging).

\section{Disclosure}

The authors report no conflicts of interest in this work.

\section{References}

1. Baylis D, Barlett DB, Patel HP, Roberts HC. Understanding how we age: insights into inflammaging. Longev Healthspan. 2013;2:8.

2. Franceschi C, Bonafè $\mathrm{M}$, Valensin $\mathrm{S}$, et al. Inflamm-aging. An evolutionary perspective on immunosenescence. Ann N Y Acad Sci. 2000;908:244-254.

3. Fisher GJ, Kang S, Varani J, et al. Mechanisms of photoaging and cronological skin aging. Arch Dermatol. 2002;138:1462-1470.

4. Brincat M, Mouniz CF, Studd JW, et al. Sex hormones and skin collagen content in postmenopausal women. Br Med J (Clin Res Ed). 1983;287:1337-1338

5. Birnbaum J, Le Moigne A, Dispensa L, Buchner L. A review of clinical trials conducted with oral, multicomponent dietary supplements for improving photoagedskin. J Drugs Dermatol. 2015;14(12):1453-1461.

6. Joven J, Rull A, Rodriguez-Gallego E, et al. Multifunctional targets of dietary polyphenols in disease: a case for the chemokine network and energy metabolism. Food Chem Toxicol. 2013;51:267-279.

7. BRASIL. Ministério da Saúde. Conselho Nacional de Saúde. Resolução no 466, de 12 de Dezembro de 2012. Aprova diretrizes e normas regulamentadoras de pesquisas envolvendo seres humanos. Diário Oficial [da] República Federativa do Brasil. Brasília, DF, n 112, 13 de Junho de 2013, Seção 1, p. 59.

8. Piérard GE, Piérard S, Delvenne P, Piérard-Franchimont C. In vivo evaluation of the skin tensile strength by the suction method: pilot study coping with hysteresis and creep extension. ISRN Dermatol. 2013;2013:841217.

9. Bogdan C, Iurian S, Tomuta I, Moldovan M. Improvement of skin condition in striae distensae: development, characterization and clinical efficacy of a cosmetic product containing Punica granatum seed oil and Croton lechleri resin extract. Drug Des Devel Ther. 2017;11:521-531.

10. Nishimoto S, Hiura N, Sato R, Suzuki K, Asano R. Effect of oral administration of gelatin and collagen peptides on the hydroxyproline content of rat's skin. J Jpn Soc Food Sci Technol (Jpn). 2002;49(3):199-202.

11. Aoki M, Suto K, Komatsu M, et al. Increasing effect of an oral intake of L-hydroxyproline on the soluble collagen content of skin and collagen fragments in rat serum. Biosci Biotechnol Biochem. 2012;76(6): 1242-1244.

12. Zague V. A new view concerning the effects of collagen hydrolysate intake on skin properties. Arch Dermatol Res. 2008;300:479-483.

13. Liang J, Pei X, Zhang Z, et al. The protective effects of long-term oral administration of marine collagen hydrolysate from chum salmon on collagen matrix homeostasis in the chronological aged skin of SpragueDawley male rats. $J$ Food Sci. 2010;75:H230-H238.

14. Oesser S, Adam M, Babel W, Seifert J. Oral administration of (14)C labeled gelatin hydrolysate leads to an accumulation of radioactivity in cartilage of mice (C57/BL). J Nutr. 1999;129:1891-1895.

15. Postlethwaite AE, Seyer JM, Kang AH. Chemotactic attraction of human fibroblasts to type I, II, and III collagens and collagen-derived peptides. Proc Natl Acad Sci U S A. 1978;75:871-875.

16. Matsuda N, Koyama Y, Hosaka Y, et al. Effects of ingestion of collagen peptide on collagen fibrils and glycosaminoglycans in the dermis. J Nutr Sci Vitaminol (Tokyo). 2006;52:211-215.

17. Hata R, Senoo H. L-ascorbic acid 2-phosphate stimulates collagen accumulation, cell proliferation, and formation of a three-dimensional tissue like substance by fibroblasts. J Cell Physiol. 1989;138:8-16.

18. Pinnel SR, Murad S, Darr D. Induction of collagen synthesis by ascorbic acid. A possible mechanism. Arch Dermatol. 1987;123:1684-1686.

19. Da-Costa-Rocha I, Bonnlaender B, Sievers H, Pischel I, Heinrich M. Hibiscus sabdariffa L. - a phytochemical and pharmacological review. Food Chem. 2014;165:424-443.

20. Peng CH, Yang YS, Chan KC, et al. Hibiscus sabdariffa polyphenols alleviate insulin resistance and renal epithelial to mesenchymal transition: a novel action mechanism mediated by type 4 dipeptidyl peptidase. J Agric Food Chem. 2014;62:9736-9743. 
21. Wang J, Cao X, Jiang H, Qi Y, Chin KL, Yue Y. Antioxidant activity of leaf extracts from different Hibiscus sabdariffa accessions and simultaneous determination five major antioxidant compounds by LCQ-TOF-MS. Molecules. 2014;19:21226-21238.

22. Hidalgo J, Flores C, Hidalgo MA, et al. Delphinol® standardized maqui berry extract reduces postprandial blood glucose increase in individuals with impaired glucose regulation by novel mechanism of sodium glucose cotransporter inhibition. Panminerva Med. 2014;56:1-7.

23. Watson RR, Schönlau F. Nutraceutical and antioxidant effects of a delphinidin-rich maqui berry extract Delphinol®: a review. Minerva Cardioangiol. 2015;63:1-12.
24. Lazzè MC, Pizz ala R, Perucca P, et al. Anthocyanidins decrease endothelin-1 production and increase endothelial nitric oxide synthase in human endothelial cells. Mol Nutr Food Res. 2006;50:44-51.

25. Kwon JY, Lee KW, Kim JE, et al. Delphinidin suppresses ultraviolet B-induced cyclooxygenases-2 expression through inhibition of MAPKK4 and PI-3 kinase. Carcinogenesis. 2009;30: 1932-1940.

26. Lim TG, Jung SK, Kim JE, et al. NADPH oxidase is a novel target of delphinidin for the inhibition of UVB-induced MMP-1 expression in human dermal fibroblasts. Exp Dermatol. 2013;22:428-430.
Clinical, Cosmetic and Investigational Dermatology

\section{Publish your work in this journal}

Clinical, Cosmetic and Investigational Dermatology is an international, peer-reviewed, open access, online journal that focuses on the latest clinical and experimental research in all aspects of skin disease and cosmetic interventions. This journal is included on PubMed. The manuscript management system is completely online

\section{Dovepress}

and includes a very quick and fair peer-review system, which is all easy to use. Visit http://www.dovepress.com/testimonials.php to read real quotes from published authors 